\title{
Ethical and Legal Challenges of Egg Donation in India
}

\author{
Dr. K. Sangeetha*
}

Assistant Professor, Tamil Nadu Dr. Ambedkar Law University, Tharamani, Chennai, India

\author{
DOI: $10.36348 /$ sijlcj.2020.v03i04.009 \\ | Received: 15.04 .2020 | Accepted: 22.04.2020 | Published: 30.04 .2020 \\ *Corresponding author: Dr. K. Sangeetha
}

\section{Abstract}

The use of donor eggs in assisted reproductive technology (ART) has increased rapidly since the first birth following the use of this technology to a woman experiencing primary ovarian failure in 1983. In 2011 (the most recent year for which statistics are available), 18,530 ART cycles in the India involved the use of donor eggs. That represents $13.9 \%$ of all ART cycles, up from approximately $8 \%$ in 1995, the first year such data were collected. In 2011, 7,902 live births resulted from the use of donor eggs. National statistics do not indicate either the number of donors or the number of recipients involved in the process. Equivalent global statistics are difficult to compile due to variable mechanisms for tracking and presenting oocyte donation practices across jurisdictions. While the benefits of oocyte donation in assisting reproduction of women who are unable to produce eggs are clear, many aspects of oocyte procurement and use remain controversial. Indeed, with the introduction of egg donation for research and cryopreservation of eggs, the controversies are increasing. This paper will focus specifically on the controversies surrounding the legality and morality of various forms of payment for egg donation, including direct reimbursement for financial expenses incurred by participating in donation, compensation for time, discomfort, and inconvenience, reward for participating in donation that goes beyond compensation, and purchase of eggs. Apart from a nearly universal perspective that oocytes should not be purchased and sold as commodities, no consensus has been reached on appropriate recompense for egg donors. Major issues in this debate include the relative acceptability of monetary payment versus payment in the form of reduced fees for other reproductive services (often as a result of egg or sperm sharing) and the factors to be considered in determining the just compensation for the time, pain, discomfort, and potential physical risk egg donors face in this process. The effects of legal interventions imposed in various national contexts on the availability of this technology, the influence of egg cryopreservation, and the use of donated eggs for research rather than reproduction are discussed.

Keywords: Compensation, Ethics, Law, Policy, Assisted Reproductive Technology, Recompense.

Copyright @ 2020: This is an open-access article distributed under the terms of the Creative Commons Attribution license which permits unrestricted use, distribution, and reproduction in any medium for non-commercial use (NonCommercial, or CC-BY-NC) provided the original author and source are credited.

\section{INTRODUCTION}

The use of donor eggs in assisted reproductive technology (ART) has increased rapidly since the first birth following the use of this technology to a woman experiencing primary ovarian failure in 1983. In 2011 (the most recent year for which statistics are available), 18,530 ART cycles in the India involved the use of donor eggs. That represents $13.9 \%$ of all ART cycles, up from approximately $8 \%$ in 1995 , the first year such data were collected. In 2011, 7,902 live births resulted from the use of donor eggs. National statistics do not indicate either the number of donors or the number of recipients involved in the process. Equivalent global statistics are difficult to compile due to variable mechanisms for tracking and presenting oocyte donation practices across jurisdictions.
While the benefits of oocyte donation in assisting reproduction of women who are unable to produce eggs are clear, many aspects of oocyte procurement and use remain controversial. Indeed, with the introduction of egg donation for research and cryopreservation of eggs, the controversies are increasing. This paper will focus specifically on the controversies surrounding the legality and morality of various forms of payment for egg donation, including direct reimbursement for financial expenses incurred by participating in donation, compensation for time, discomfort, and inconvenience, reward for participating in donation that goes beyond compensation, and purchase of eggs.

Apart from a nearly universal perspective that oocytes should not be purchased and sold as commodities, no consensus has been reached on appropriate recompense for egg donors. Major issues in 
this debate include the relative acceptability of monetary payment versus payment in the form of reduced fees for other reproductive services (often as a result of egg or sperm sharing) and the factors to be considered in determining the just compensation for the time, pain, discomfort, and potential physical risk egg donors face in this process. The effects of legal interventions imposed in various national contexts on the availability of this technology, the influence of egg cryopreservation, and the use of donated eggs for research rather than reproduction are discussed.

ETYMOLOGICALLY, THE term embryo comes from the Greek noun 'embryon', which means 'ingrow'. According to the Stedman's Medical Dictionary, the embryo is an organism in the early stages of development, from conception until the end of the eighth week. Embryo freezing is still not very popular in India $\left.{ }^{1}\right]$. Using donated embryo in India is usually a matter of secrecy as couples do not want their infertility revealed and disturb the social and biological connection between the mother, father and child. The use of donor gametes, either in the form of donor sperm or donor oocytes, is common practice in ART. The development of in vitro fertilization (IVF) and related techniques has made oocyte and embryo donation another option for infertile couples. It is now possible to take oocytes, or eggs, out of a women's body, fertilize them with sperm and create an embryo in a laboratory. The embryo may then be transferred by the doctor into a woman's uterus, possibly resulting in a pregnancy and eventually the birth of a child $\left[{ }^{2}\right]$.

The use of donor sperm can be traced to the 1800 's. In the mid-1980s, oocyte donation was started. During the 1980s, clinical use of IVF and associated research involving human embryos spread quickly among the developed nation. The advent of in vitro fertilization (IVF), followed shortly by embryo cryopreservation, transformed both the medical and legal landscape involving reproduction. The large majority of embryo donors are couples who have completed their families through IVF and have had the spare embryos cryopreserved [3]. Prior to 2002 the

\footnotetext{
${ }^{1}$ Former Miss World Diana Hayden, 42, gave new hope to women who wish to delay their motherhood, when she gave birth to her first child born out of her egg that was frozen eight years ago.

${ }^{2}$ A, Bharadwaj, "Why adoption is not an option in India: the visibility of infertility, the secrecy of donor insemination, and other cultural complexities" 56 Soc Sci Med 1867-1880 (2003) cited in A. Widge, J. Cleland, "Negotiating boundaries: Accessing donor gametes in India", 3 (1) $F, V \& V I N$ OBGYN 53-60(2011) available at: https://www.ncbi.nlm.nih.gov/pubmed/24753849
}

(Last visited on 23.01.2018).
Success rate of live births from frozen eggs was 1-3\% globally, with few babies born from frozen eggs over decades of attempts.

The use of a donated embryo in assisted conception was first reported by Trounson et al. in 1983, when a female patient was successfully treated using an embryo created from a donor egg and donor sperm. Though few couples are comfortable with embryo freezing and donation, many have moral and ethical dilemmas regarding the freezing and donation of embryos. For those that believe that life is created at the moment of conception, each frozen embryo represents a life and, if unused, a life unfulfilled. The commercialization of embryos has raised a variety of ethical-moral questions regarding the rights of the unborn children their ability to know their biological parent, moral status of embryos etc. Embryo donation is an accepted method in assisted reproduction techniques in many parts of the world, for example in the USA, Australia and in European countries such as Belgium, Greece, Russia, Spain and the UK. Some feminists and others have viewed the sale of eggs, and presumably embryos, as commodification, arguing that such markets cheapen human life. Some individuals believe that embryos have greater moral standing than do gametes.

Although there is no law to regulate assisted reproductive technology in India there are non-binding guidelines issues by the Indian Council of medical Research (ICMR) which called as National Guidelines for Accreditation, Supervision \& regulation of ART clinics in India 2005(hereinafter referred as ART Guidelines). These guidelines envisage the regulation, licensing, and supervision of clinics inter alia engaged in assisted reproductive technology or research on human embryos.

Facilities for cryopreservation are an essential component of an ART clinic as they are to be used under a variety of conditions such as those described below. Men, who are likely to suffer from psychological stress at the time of ovum pick-up or those who cannot be present at the time of ovum pick-up, are recommended to have their semen frozen for use at the appropriate time. One of the important reasons for freezing semen from donors is that any donor semen has to be quarantined for six months. The safety of using frozen sperm has been abundantly proven, both by experimental work and the actual results in humans. Matters of concern are the donor's health and the necessity to avoid donors who are infected with venereal diseases, hepatitis B or C, or HIV. One of the drawbacks of sperm freezing is an approximate $20 \%$ loss in motility after thawing. 
Donors whose semen is frozen for future use are required to report to the semen bank six months after donation to be checked for HIV, HBV or HCV infection/disease status $\left[{ }^{3}\right]$.

Embryos are routinely cryopreserved to enable storage of supernumerary embryos, as up to a maximum of only three embryos is allowed for transfer to avoid the risk of multiple pregnancies. Human embryos can be successfully cryopreserved at any stage from zygote to blastocyst, using 1, 2 propanediol (PROH) or dimethylsulfoxide (DMSO) for zygotes and cleaved embryos and glycerol for blastocysts. The formation of ice crystals is of concern during embryo freezing. Using programmed, slow freezers reduces this problem considerably, and slows cooling $\left[{ }^{4}\right]$.

\section{Health Issues}

Egg donors are hyper-ovulated to stimulate the production of a maximum number of eggs. Egg harvesting is done under anesthesia procedures that could pose health risks, including ovarian hyper stimulation syndrome. Women donating oocytes must undergo IVF. Due to the inherent medical risks associated with IVF, including ovarian hyper stimulation syndrome and surgical risks, informed consent is another major issue of concern. Additionally, it is considered an ethical prerequisite that oocyte donors participate voluntarily and without coercion or undue influence. Some have expressed concern that financial compensation of oocyte donors may lead to exploitation as women may proceed with oocyte donation against their own best interests, given the inherent medical risks involved. The "buying or selling" of human gametes is inherently immoral, as it lead to commodification of embryo.

\section{Anonymity of Donor}

An issue of great controversy is whether children born using donated sperm should be able to know the identity of the sperm donor. Indeed, the ability of human beings to know their genetic roots is universally important, for the sake of self-identity. Either egg and sperm donors may choose to or not to be anonymous, though the vast majority in both groups generally chooses anonymity. Recently, however, there is, increasing consideration of the

\footnotetext{
${ }^{3}$ Priya Selvaraj, Kamala Selvaraj, et.al. GG Hospitals Chennai, "Successful birth of the first frozen oocyte baby in India" 2(1) J HRS 41- 44 (2009 Jan-Jun) available at:

https://www.ncbi.nlm.nih.gov/pmc/articles/PMC270069 1/(Last visited on 24.01.2018).

4 Margaret E. Swain, "Oocyte Donation: Legal Aspects" in J.M. Goldfarb (ed.), Third-Party Reproduction: A Comprehensive Guide 32 (Springer
} New York 2014) (Last visited on 24.01.2018). rights of offspring. Advocates for allowing either gamete donors or their offspring to break anonymity cite the medical advantages of sharing medical information with their genetic offspring, in the case of the donor, or learning about their genetic history directly, in the case of offspring. Others simply argue that both donors and offspring have an inherent right to meet and develop a relationship.

Recent court rulings suggest that these rights will become more visible in the coming future. For example, in the British case Rose v Secretary of State for Health $\left[{ }^{5}\right]$, the court ruled that children born as a result of assisted reproduction had a right under Article 8 of the European Convention on Human Rights to discover information about their genetic parentage. However, a gamete donor who donated with the promise of anonymity also had a right under Article 8 to protect their anonymity.

The ethical and legal issues surrounding anonymity and gamete donation are sure to be a centrally debatable issues within the field of ART. Children born using donated sperm have spoken of being incomplete without the full knowledge of their genetic origins. However it is not clear from research whether giving identifying information creates the feeling of completeness that these individual hope for.

IVF cycles often result in transferring several embryos and cryopreserving other embryos produced by the cycle, presumptively for the purpose of future pregnancy. However, in many instances, these surplus embryos are never used by the genetic parents and therefore are stored indefinitely. The number of such embryos stored internationally is surprisingly high. In the United States alone, it is estimated that over 400,000 embryos are currently cryopreserved, many of which will not be used by their genetic parents. The ethical and moral issues surrounding how to deal with these surplus embryos have been the source of much debate. In general, four possible fates for these embryos exist: (1) thawing and discarding, (2) donating to research, (3)indefinite storage, (4)donating the embryos to another couple for the purposes of uterine transfer.

A new study, by the Society for Assisted Reproductive Technology and the RAND Corporation, found that fertility clinics in the United State have nearly 400,000 frozen human embryos in storage twice the highest previous estimate. The survey of 430 clinics showed that 88.2 percent of the embryos are being stored for possible future use. About 11,000 are set aside for scientific research. About 9,000 are designated for infertile couples. Another 9,000 will be thawed and destroyed. All of these strategies have staunch supporters and detractors. Not 
surprisingly, there are myriad laws in different countries governing many aspects of how a human embryo that has been cryopreserved may be handled. The use of embryos for the purpose of research, specifically as it relates to human stem cells, has also been a source of fierce debate internationally and has resulted in substantial regulation that varies substantially from nation to nation.

The disposition of unused embryos not only raises moral and ethical dilemmas for the couples who create them but also for society as a whole. To keep embryos for possible future use is not initially a controversial issue. It only becomes one when embryos have been frozen for several years and their viability or quality for transfer comes into question. How long an embryo can be frozen and still be safe to use in IVF is not known. The Catholic Church does not speak directly about the issue of discarding embryos because it considers ART, and all of its ramifications, to be unacceptable. The destruction of extra embryos is permissible by Jewish law if it is done passively by letting them thaw and die on their own. In most Protestant faiths, disposition of embryos is a personal concern of couple involved.

The use of frozen embryo in stem cell research has also created huge controversy. Until an embryo reaches the sixty-four-cell stage, cells of the embryo are capable of transforming themselves into any of the 220 types of cells in human body. Scientists are searching for ways to trigger stem cells to develop into specific types of cells. When specific triggers for each type of cell are found, it is hoped that new tissues can be grown to treat persons with diabetes, Parkinson's disease, Alzheimer's disease, and other conditions. This is the ultimate goal of the scientists doing stem cell research. Many people believe that this is a laudable goal but others disagree. When stem cell lines are created from frozen embryos, the embryos themselves are destroyed. For those who believe that life starts when an egg is fertilized, destroying embryos is a type of murder. For them, the use of frozen embryos for stem cell research is unacceptable.

Yet embryonic stem cell research is very controversial because the derivation of embryonic stem cells destroys the embryo. Thus, the morality of embryonic stem cell research depends primarily on the morality of destroying human embryos, raising the question of the moral status of the human embryo. Creating embryos for research treats the embryo as a mere object. Doing this 'may increasingly lead us to think of embryos generally as means to our ends rather than as ends in themselves'. Studies say that embryonic stem cell has shown two major biological
First, contrary to the original hope, embryonic stem cells are rejected when transplanted into a genetically non-identical recipient. Thus the recipient would have to be treated to suppress the immune system. This treatment is very severe and currently associated with significant complications. Second, some of the animal data show that the differentiated embryonic stem cells are not entirely stable after transplantation. In particular, there have been some embryonic stem cells that develop into tumors.

In Germany, the law bans the creation of embryos using the in-vitro fertilization (IVF) method for purely research purposes. In the United Kingdom, legislation has been enacted permitting the destruction of unclaimed embryos after five years. In Europe and the US, stem cell research has become so controversial because it involves embryos. It is thus opposed by those who believe that life begins at conception. Article 4 of the American Convention on Human Rights (ACHR) states: "Every person has the right to have his life respected. This right shall be protected by law and, in general, from the moment of conception. No one shall be arbitrarily deprived of his life". This mandate to protect life from the moment of conception is based on the understanding that the right to life exists from fertilization onwards. Otherwise, there would be no life to protect at that stage. Thus, the ACHR not only declares that unborn children have a right to life, but also that they are persons. But the Inter-American Commission on Human Rights, one of two adjudicatory bodies that interprets and monitors compliance with the American Convention, has clarified that this protection is not absolute."

The ninth paragraph of the Preamble of the Convention on the Rights of the Child also does so when quoting the Declaration of the Rights of the Child. It states: "the child, by reason of his physical and mental immaturity, needs special safeguards and care, including appropriate legal protection, before as well as after birth." Constitutions of some of the countries also protect life from the moment of conception.

India's stem cell research has been described as the next big thing to hit India after the country's software revolution. Embryos are already travelling from IVF clinics in India to public and private research laboratories trying to isolate stem cell both in India and elsewhere. The ICMR in its ethical guidelines on assisted reproduction allows stem cell research with informed consent from the embryo donor and provided research begins within 14 days of embryo formation. But these guidelines are not binding; nor is there a monitoring and enforcement agency. 
The mainstream Hindu view is that deliberate destruction of an embryo is homicide. The Vedas, the oldest of the sacred Hindu texts, emphasize the sanctity of life. The purpose of human life is to make progress towards this liberation from rebirth through. But the destruction of an embryo interrupts this process of reincarnation because according to traditional Hinduism, the soul is reborn from its previous life at the moment of conception. This means destroying an embryo means destroying a new life with a soul and this can interfere with progress towards liberation from rebirth. The Catholic Church, as well as Jewish law, does not sanction the use of frozen embryos for stem cell research because embryos are destroyed in the process. On the other hand, Islamic law allows the use of frozen embryos for stem cell research that is intended for therapeutic uses as long as prior consent of the couple who created the embryo is obtained.

\section{CONCLUSION}

To conclude, the use of ART has revolutionized the life of humans, it fulfilled the hope of the despaired infertile people, made it possible for them to have their genetically linked child, but on the other hand the use of ART raised the number of social, ethical, moral, economic, religious, and health related issues which put a big question mark on the use of ART. Embryo freezing and donation also raised very serious issues which should be addressed by law. The guidelines formulated by ICMR are not binding and there is no monitoring agency. The law and policy should be formulated with the consultation with different stake holders. Following are the few suggestions that may be taken into consideration while drafting the policy:

1. The medical professionals dealing with ART are governed only by the norms of ethics and non-binding guidelines. The liabilities and responsibilities of medical and technical professionals are major issues which should be dealt by the specific legal norms and principles.

2. There are no standard treatment protocols for ART including embryo freezing and donation in India. Legitimate social issues that go beyond the exclusive expertise of doctors and scientists or market choice by patients need to be accommodated within the regulatory regime.

3. There is a need to make special provisions to ensure the welfare of children in the case of child born through embryo donation.

4. The social-ethical and religious norms should not be overlooked by undergoing the procedure of embryo freezing and donation.

5. There should be proper regulation of embryo freezing and donation in the context of stem cell research. Use of embryo for stem cell research should be strictly prohibited.

6. The rights as well as responsibility of the donor of embryo should be formulated by law.

7. Embryo freezing and donation generated moral-ethical dilemmas as well as legal disputes which involve status of embryo, cryopreservation, stem cell research, payment for donation etc. law and policies should be made to address these issues.

8. The commercial use of embryo should be prohibited through proper legislation. Sale and purchase of embryo should be made punishable under the law. 